\title{
Epigenetics in the Agricultural Sector
}

\author{
Waleed Fouad Abobatta* \\ Horticulture Research Institute, Agriculture Research Center, Egypt
}

Submission: June 27, 2018; Published: August 15, 2018

"Corresponding author: Waleed Fouad Abobatta, Horticulture Research Institute, Agriculture Research Center, 9 Gamaa, Egypt, Tel +201224296948; Email: wabobatta@yahoo.com

\section{Summary}

Epigenetics is the study of heritable changes in gene expression that happen without any change in the DNA sequence. The main epigenetic mechanisms, including DNA methylation, histone modifications, and microRNA expression, can be caused by environmental reasons. The aim of this work explains that epigenetic modifications may be due to effects of environmental stress on plant growth and productivity. The study of epigenetic-based mechanisms in the plant is an emerging field; gene expressions are modulated and reprogrammed in response to environmental stress challenges. Due to increasing global population, in the same time the availability of arable lands is decreased regularly and the severe effects of climate change problem, therefore, it is essential to understand the mechanisms that plants have progressed to adapt with varied environments stress, and in particular how plant types adapt with various kinds of biotic and abiotic stress. The main role of epigenetics study is understanding the role of the epigenetic component in regulates plant gene expression and the plant phenotype, and how the epigenome workings as a great source of diversity for main agronomical characters and on how it could use, in crop breeding and implementation programs, it would be of benefit to humanity for next era, numerous papers have studied the effects of environmental exposures and epigenetic markers that modify epigenetic states of plants and refers those epigenetic modifications may be one of the mechanisms by which abiotic stress can have positive effects on plant growth.

Keywords: Epigenetics; DNA methylation; Histone modifications; Environmental stress and Plant crops.

\section{Introduction}

For different centuries, scientists has been thought that DNA was the only source to determine the productivity, infection with pathogens or other changes in plants, but lately it has been found that epigenetic changes play important role could be at the same level of DNA changes, now researchers are observing the role of environmental conditions in epigenetic modifications to know if there is a change in gene expression and phenotype due to abiotic stresses condition, Plants are considered as the masters of epigenetic regulation due to their ability of rapid and reversible modification of their epigenetic state and also preserving a stable "memory" of it, in different conditions plants are grown under harsh environmental situations which decrease the total production, and may be survival, therefore, they have advanced complicated mechanisms at molecular level to survive under critical conditions to hastily obtain and resist environmental stress during their life cycle. Different kinds of stressors can induce transient, stable, and heritable change in gene expression that occurs without changes in DNA sequences, in general, plant response to external stress mostly temporary, whereas in some instances cases they persist longer.

Epigenetics has grown promptly over the last two decades as a contemporary field of biology; epigenetics regulation is the heritable meiotic or mitotic genetic change in gene expression that happens in the absence of modifications in DNA sequences.
There are different factors like stress signals, hormones, metabolites, free radicals are affecting genes encoding various epigenetic regulators such as histone variants, chromatin remodeling factors, transcription factors or DNA and histones modifying enzymes, all of these factors cause epigenetic changes in gene expression [1]. Environmental stress has been shown to modulate epigenetic marks; there is more attention in estimating the modifications that environmental exposures may produce on epigenetic states, and whether such changes might activate pathways leading to detrimental effects on plant growth [2]. Epigenetic is an important attribute to clarify the unknown changes in plants, with proper expression from new transgenic segments [3].

\section{What is epigenetics?}

\section{Definition of Epigenetics}

Epigenetics is the level of control that sits above the genes determine which genes are turned on and which genes are turned off. From another side, epigenetics means a variety of molecular mechanisms are involved in epigenetic regulation of gene expression and chromosomal stability, including histone modifications, non-coding RNA, and DNA methylation [4]. The term epigenetic is often used to describe a variety of unexpected patterns of gene regulation. 
II. Epigenetic trait: Is a stably heritable phenotype resulting from changes in a chromosome without alterations in the DNA sequence [5].

\section{Epigenetics science}

It is the study of chromosome changes that change the expression of genes without any modification in the gene sequences or Epigenetics is the study of heritable changes in gene expression that occur without a change in the DNA sequence. Remarkably, different stresses conditions may be activated and stimulus epigenetic alters and changes genic expression level by various mechanisms like DNA methylation, histone modifications and miRNA therefore, Epigenetics considered the most continuously progressing branch since the past two decades $[6,7]$.

\section{Why we need Epigenetic in crops?}

Breeding techniques over the last several centuries have led to the loss of genes that could be helpful to plant geneticists looking for drought, tolerant, heat, withstanding varieties that could be valuable for agricultural climate change adaptation. This was a genetic bottleneck and led to limited diversity [5]. Epigenetic research could save scientists from going into the wild to collect seeds to reclaim lost genetic material; we now know that many new genetically engineered plants and animals are as safe as conventionally grown alternatives. But the path to approval for new GMOs remains lengthy and costly.

\section{What's the role of Epigenetics in Plant Processes?}

Crop agriculture has two major problems, which are the deficiency in nutrient and in water supply, also, many crop species are clonally propagated, but, it doesn't take into account the epigenome. Epigenetics may play important roles to address these challenges through various processes like:

a. Developmental regulation.

b. Responses to environmental stimuli.

c. Local adaptation.

d. Controls the time of flowering.

\section{Epigenetic mechanisms}

In last decades, it has been revealed that epigenetic mechanisms play an important role in the response of various plant kinds to environmental stress. DNA methylation. Plants are known for their complex gene silencing machinery, including cytosine methylation, histone modifications and a wide variability of small RNAs [8]. There are numerous epigenetic mechanisms identified and molecular mechanisms are involved in epigenetic regulation of gene expression and chromosomal stability, including DNA methylation, histone modifications, chromatin remodeling, and non-coding RNA and DNA methylation. Alters in gene expression suggested by stress signals follow posttranslational histone modifications, DNA methylation, histone variant incorporation, and the action of chromatin remodeling factors [9].

Plants make varied use of DNA methylation as an epigenetic mark and undergo histone modifications to carry out transcriptional as well as posttranscriptional gene silencing programs. Furthermore, current research on epigenetic mechanisms indicates that DNA methylation, histone posttranslational modifications, and small non-coding RNAs are intricate in almost every trait of plant life including important traits like flowering period, fruit growth, responses to environmental conditions, and plant resistance. Epigenetic alterations can be inherited during mitosis and meiosis phases, through epigenetic memory, the plants can more efficiently respond to future stressful conditions, thereby increasing their potential for environmental adaptation, understanding of the epigenetic mechanisms that take part in plants' response to changes in environmental conditions will enhance our realization of adaptations of plants to stress conditions [10]. Understanding epigenetics mechanisms may help to improve plant productivity and enhancement breeding practices in different plant kinds, "the presence of stress memory keeps plants prepared for upcoming stresses".

\section{Epigenetics Mechanism Including}

1) DNA methylation.

2) Histone modifications (acetylation, methylation, phosphorylation, ubiquitination, biotinylation, and simulation).

3) Chromatin remodeling.

4) Small RNA (miRNA and siRNA).

\section{DNA methylation}

DNA methylation targets the promoter region of the genes transcriptional silencing when methyl groups added to DNA it stop the gene from being "seen" by form 5-methylcytosine (5$\mathrm{mC}$ ), the methyl groups basically block other proteins from binding to the promoter region due to this areas contains a high number of C (cytosine) and G (guanine) DNA bases, the cytosine or $\mathrm{C}$ residues in these areas can receive methyl groups added to them then the gene sequence cannot be read so genes are switched off and no transcription after methylated $[11,12]$. Changes in DNA methylation in response to drought stress cause differential expression of stress-responsive genes in the drought-tolerant variety of rice [13]. DNA methylation is one of the most well-known epigenetic marks, it can be found in the coding regions of genes in many organisms, ranging from plants to humans, it targets the promoter region of the genes; this process is catalyzed by an enzyme known as DNA methyl transferase (DNMT).

\section{Role of DNA methylation}

Increasing evidence has shown that DNA methylation plays a significant role as follow: 
a. It plays a very important role in several key processes as well as genomic imprinting, $\mathrm{X}$-chromosome inactivation.

b. Suppression of repetitive element transcription and transposition.

c. Most DNA methylation is essential for normal development [14].

d. Removing methyl marks, known as DNA demethylation, is carried out by a family of enzymes called TET enzymes [15].

Demethylation of DNA is a significant epigenetic mark for stress-induced gene expression, the loss of methylation may also expose new phenotypes, including traits that could be advantageous to crop species; therefore, if we can change the methylation, we can create heritable phenotypic variation. During 2015 growers of the African oil palm observed that there are about 10 to 20 percent of trees weren't producing oil, after research, them found that this palm suffered from the activation of a transposon that had lost its methylation and interrupted a gene critical for oil production [ $\mathrm{CHH}$ methylation] is changed inefficiently and sometimes in the wrong place [15]

\section{Histone methylation}

Post-translational histone modifications of lysine residues at the $\mathrm{N}$-terminal tails of histone proteins generate different "histone code" that determine chromatin structure during nuclear events [16]. There is emerging evidence explained the role of histone modifications in transcription regulation of stressresponsive genes in plants $[17,18]$. Also, histone methylation has an active role in the regulation of plant hormone biosynthesis in common bean [18].

\section{Epigenetic markers}

Epigenetic markers are chemical regulate genes that sit over the DNA sequence, it explores the consequences of thermal and ionic variation on the behavior of plant under stress conditions, there are different epigenetic marks like DNA cytosine methylation and histone variants as H2A.Z. Epigenetic markers can be move from cell to cell and from generation to generation [19].

\section{The epigenome}

The epigenome contains the chemical compounds that express DNA what to do, where to do it and when to do it, all of which can be functions undertaken by any one of organism cells using the same identical DNA toolkit e.g. grow leaves vs. flowering, grow a finger vs. grow a nose, in other words, if DNA is hardware and epigenome as the software that controls hardware.

\section{What is Epigenomics?}

Epigenomics is a global study of epigenetic changes across the entire genome, or it is the study of the all the epigenetic changes in a genome of a cell, such genome is also called as epigenome [20].

\section{Epialleles}

This refers to the genes with identical nucleotide sequence but altered expression abilities due to epigenetic events [21]. Recent studies on abiotic stress signaling have explained the role of the epigenome in adaptable stress-induced gene expression, either by modulating chromatin structure through histone modification and/or DNA methylation or through non-coding RNA [17].

\section{Conclusion}

Epigenetic modifications are relatively stable over time and may be influenced by the environmental conditions; therefore, exposure to abiotic stress could lead to epigenome modifications, nowadays, it is now known that epigenetic modifications control gene expression by modulating the access of regulatory complexes to the genome. The previous researches refer that abiotic stress can have positive effects on plant growth through epigenetic modifications, and how the epigenome workings as a great source of diversity for main agronomical characters and on how it could use in crop breeding and implementation programs, up to now many genetic pathways and regulatory mechanisms have been elucidated, The major role of epigenetics science is regulated plant gene expression and the plant phenotype; it would be of benefit to humanity for next era. Further studies obviously are required for a full understanding of different epigenetics mechanisms in plants.

\section{References}

1. Achrem M, Skuza L, Kalink A, Szucko I, Filip E, et al. (2012) Role of epigenetic mechanisms in plant response to low temperature. Acta Biologica Cracoviensia Series Botanica 54(1): 7-15.

2. Baccarelli A, Bollati V (2009) Epigenetics and environmental chemicals. Curr Opin Pediatr 21(2): 243-251.

3. Madhusudhan (2012) Importance of Epigenetic in Plants. J Bioengineer Biomedical Sci 5(2)

4. Tollervey J, Lunyak VV (2012) Epigenetics Judge, jury and executioner of stem cell fate. Epigenetics 7 (8): 823-840.

5. Abobatta WF (2018) Role of Epigenetics in Agriculture. Principle of Epigenetics Summit, Egypt.

6. Riggs AD, Martienssen RA, Russo VEA (1996) Introduction. In Epigenetic mechanisms of gene regulation (ed. Russo VEA, et al.), pp. 1-4 Cold Spring Harbor Laboratory Press, Cold Spring Harbor, New York, USA.

7. Collotta M, Bertazzi PA, Bollati V (2013) Epigenetics and pesticides. Toxicology.

8. Bej S, Basak J (2017) Abiotic stress induced epigenetic modifications in plants: how much do we know? In: Rajewsky N, Jurga S, Barciszewski J (ed n.), Plant epigenetics. Springer, Cham, Germany.

9. Lämke J, Bäurle I (2017) Epigenetic and chromatin-based mechanisms in environmental stress adaptation and stress memory in plants. Genome Biology 18:124.

10. Kitamura A, Miyauchi N, Hamada H, Hiura H, Chiba H, et al. (2015) Epigenetic alterations in sperm associated with male infertility. Congenit Anom 55:133-144.

11. Moore LD, Le T, Fan G (2012) DNA methylation and its basic function. Neuropsychopharmacology 38(1): 23-38. 
12. Paul A, Dasgupta P, Roy D, Chaudhuri S (2017) Comparative analysis of Histone modifications and DNA methylation at OsBZ8 locus under salinity stress in IR64 and Nonabokra rice varieties. Plant Mol Biol 95(1-5): 63-88.

13. Wang YM, Lin XY, Dong B, Wang YD, Liu B (2004) DNA methylation polymorphism in a set of elite rice cultivars and its possible contribution to inter-cultivar differential gene expression. Cell Mol Biol Lett 9(3): 543-556.

14. Law JA, Jacobsen SE (2010) Establishing, maintaining and modifying DNA methylation patterns in plants and animals. Nat Rev Genet 11(3): 204-220.

15. Gopalakrishnan S, Van Emburgh BO, Robertson KD (2008) DNA methylation in development and human disease. Mutat Res 647(1-2): 30-38.

16. Jenuwein T, Allis CD (2001) Translating the histone code. Science 293(5532): 1074-1080.
17. Chinnusamy V, Zhu JK (2009) Epigenetic regulation of stress responses in plants. Curr Opin Plant Biol 12(2): 133-139.

18. Kim JM, Sasaki T, Ueda M, Sako K, Seki M (2015) Chromatin changes in response to drought, salinity, heat, and cold stresses in plants. Front Plant Sci 6:114.

19. Herrera CM, Bazaga P (2013) Epigenetic correlates of plant phenotypic plasticity: DNA methylation differs between prickly and nonprickly leaves in heterophyllous Ilex aquifolium (Aquifoliaceae) trees. Botanical Journal of the Linnean Society 171(3): 441- 452.

20. Russell PJ (2010) I Genetics: A Molecular Approach. San Francisco, CA Pearson Education, Inc, UK.

21. Weigel D, Colot V (2012) Epialleles in plant evolution. Genome Bio 13(10): 24 .

Your next submission with Juniper Publishers will reach you the below assets

- Quality Editorial service

- Swift Peer Review

- Reprints availability

- E-prints Service

- Manuscript Podcast for convenient understanding

- Global attainment for your research

- Manuscript accessibility in different formats

(Pdf, E-pub, Full Text, Audio)

- Unceasing customer service

Track the below URL for one-step submission https://juniperpublishers.com/online-submission.php 